\title{
BMJ Open Knowledge, attitudes, perceptions and habits towards antibiotics dispensed without medical prescription: a qualitative study of Spanish pharmacists
}

Juan Vazquez-Lago, ${ }^{1}$ Cristian Gonzalez-Gonzalez, ${ }^{1}$ Maruxa Zapata-Cachafeiro, ${ }^{1}$ Paula Lopez-Vazquez, ${ }^{1}$ Margarita Taracido, ${ }^{1,2}$ Ana López, ${ }^{3}$ Adolfo Figueiras ${ }^{1}$

To cite: Vazquez-Lago J, Gonzalez-Gonzalez C, ZapataCachafeiro M, et al. Knowledge, attitudes, perceptions and habits towards antibiotics dispensed without medical prescription: a qualitative study of Spanish pharmacists. BMJ Open 2017;7:e015674. doi:10.1136/ bmjopen-2016-015674

- Prepublication history and additional material for this paper are available online. To view these files please visit the journal online (http://dx.doi. org/10.1136/bmjopen-2016015674).

Received 5 January 2017 Revised 15 June 2017 Accepted 21 June 2017

\section{CrossMark}

${ }^{1}$ Department of Preventive Medicine and Public Health, University of Santiago de Compostela, Santiago de Compostela, A Coruña, Spain ${ }^{2}$ Consortium for Biomedical Research in Epidemiology and Public Health (CIBER en Epidemiología y Salud Pública - CIBERESP), Santiago de Compostela, Spain ${ }^{3}$ Department of Clinical Psychology and Psychobiology, University of Santiago de Compostela, Santiago de Compostela, A Coruña, Spain

Correspondence to Dr Juan Vazquez-Lago; juan.manuel.vazquez.lago@ sergas.es

\section{ABSTRACT}

Objective To investigate community pharmacists' knowledge, attitudes, perceptions and habits with regard to antibiotic dispensing without medical prescription in Spain.

Methods A qualitative research using focus group method (FG) in Galicia (north-west Spain). FG sessions were conducted in the presence of a moderator. A topic script was developed to lead the discussions, which were audiorecorded to facilitate data interpretation and transcription. Proceedings were transcribed by an independent researcher and interpreted by two researchers working independently. We used the Grounded Theory approach.

Setting Community pharmacies in Galicia, region Norwest of Spain.

Participants Thirty pharmacists agreed to participate in the study, and a total of five FG sessions were conducted with 2-11 pharmacists. We sought to ensure a high degree of heterogeneity in the composition of the groups to improve our study's external validity. Pharmacists' participation had no gender or age restrictions, and an effort was made to form FGs with pharmacists who were both owners and non-owners, provided in all cases that they were Official Colleges of Pharmacists-registered community pharmacists. For the purpose of conducting FG discussions, the basic methodological principle of allowing groups to attain their 'own structural identity' was applied. Main outcome measurements Community pharmacists' habits and knowledge with regard to antibiotics and identification of the attitudes and/or factors that influence antibiotic dispensing without medical prescription.

Results Pharmacists attributed the problem of antibiotics dispensed without medical prescription and its relationship to antibiotic resistance to the following attitudes: external responsibility (doctors, dentists and the National Health Service (NHS)); acquiescence; indifference and lack of continuing education.

Conclusions Despite being a problem, antibiotic dispensing without a medical prescription is still a common practice in community pharmacies in Galicia, Spain. This practice is attributed to acquiescence, indifference and lack of continuing education. The problem of resistance was ascribed to external responsibility,

\section{Strengths and limitations of this study}

- The generalisation of the results could also be compromised due to the intrinsic characteristics of the pharmaceutical system in Spain. In the system of pharmaceutical provision in Spain, antibiotics necessarily require a prior prescription by the physician, and all drugs must always be dispensed by pharmacies and cannot be purchased in other types of establishments.

- The focus group technique seeks the interaction of all the members of the group and ensures the identification of all the dimensions of the problem investigated while simultaneously increasing the subjective validity of each identified idea.

- Proceedings were transcribed and interpreted by an independent researcher. Any points of disagreement were discussed and resolved by consensus.

- Possible lack of generalisation of findings to health systems in other countries.

including that of patients, physicians, dentists and the NHS.

\section{INTRODUCTION}

Antibiotic resistance poses a major threat to clinical efficacy and is an important problem for global public health. Resistance is an inescapable consequence of antibiotic use, ${ }^{1}$ but it increases drastically with misuse and abuse. ${ }^{23}$ It is thus imperative to improve antibiotic use, ${ }^{4}$ particularly in outpatient settings where $90 \%$ of the consumption occur. ${ }^{5}$

One of the chief loopholes requiring attention is the dispensing of antibiotics without a prescription, a major problem in some countries. ${ }^{6}$ Whereas outpatient use of antibiotics is restricted to prescription-based consumption in northern Europe, the USA and Canada, access to antibiotics dispensed 
without medical prescription is nevertheless commonplace in the rest of the world. ${ }^{6-8}$ In Spain, dispensing antibiotics legally is done only through prescriptions, and the National Health System (NHS) covers the expenses of almost the entire population. ${ }^{9}$ Due to population density characteristics in our territory, community pharmacists are the first point of contact for patients, as part of the healthcare team. Therefore, up to one-third of all outpatient antibiotics dispensed are not prescribed by physicians. ${ }^{3}{ }^{10}$ Despite the fact that the European Union encourages Member States to restrict the use of systemic antibiotics and recommends that such drugs be exclusively consumed under medical prescription, the dispensing of antibiotics without prescription is still a common practice. ${ }^{11}$

Accordingly, this study sought to conduct a qualitative analysis of community pharmacists' knowledge, attitudes, perceptions and habits with regard to antibiotic dispensing in Galicia, Spain.

\section{METHODS}

\section{Study design}

We used the focus group (FG) method to ascertain pharmacists' attitudes, knowledge and views concerning the dispensing and use of antibiotics in Galicia, Spain. The FG method was used to explore community pharmacists' habits and knowledge with regard to antibiotics and to identify the attitudes and/or factors that influence their being dispensed. We decided to use the FG technique because the interaction of group members tends to ensure that all the dimensions of the problem assessed are brought to light, information is simultaneously obtained on the subjective validity of various members of the group, and in addition, it is a rapid technique for generating such information. ${ }^{12} \mathrm{~A}$ theoretical model based on a previous systematic review was constructed for the purpose of drawing up an agenda and a script for FG, ${ }^{13}$ which was to be followed during the group sessions to facilitate the identification of attitudes and/or factors. The script for FG can be seen in the online supplementary materials (supplementary file 1 and supplementary file 2).

The programme for conducting meetings in the various FGs was designed with a dual purpose, namely, to address: (1) the dispensing of antibiotics without a prescription and (2) individual points of view regarding antibiotic-dispensing practices among pharmacists. Basing our study on a previous one undertaken in a population of physicians ${ }^{14}$ and adapting it to the specific characteristics of pharmacists, we defined the script in attempt to cover the following factors/attitudes: acquiescence; indifference; external responsibilities and lack of continuing education. For the purposes of clarity and ease of comprehension, the four attitudes are defined in box.

\section{Box Definition of studied attitudes}

- External responsibility: the responsibility of another professional or the National Health Service for the sale of antibiotics without a medical prescription;

- Acquiescence: the ease with which antibiotics are dispensed to customers. This is associated with better customer loyalty. Part of such complacency is due to patient pressure, which comes in the form of different reasons given by a patient to obtain antibiotics without a prescription;

- Indifference: a lack of interest in terms of the patient's illness, dispensing procedures or helping resolve patients doubts;

- Lack of continuing education: lack of knowledge of pharmacist due to a bad continuing education and bad knowledge upgrade from the point of view of quantity and quality;

- Lack of continuing education can be seen from three different perspectives: (1) from a legal standpoint (ignorance of the legal consequences of dispensing antibiotics without prescription); (2) from a public health standpoint (ignorance of the consequences of dispensing antibiotics without a prescription, whether for the individual-individual point of view-or the communityecological point of view-in terms of resistances, etc) or (3) from a pharmacological standpoint (pharmacists' ignorance of the pharmacotherapeutic issues of antibiotics).

\section{Study population and settings}

In Spain, many drugs, including antibiotics, may only be dispensed under medical prescription. The dispensing of drugs takes place in community pharmacies, which must be owned by a registered pharmacist.

The study population comprised community pharmacists in Galicia. Galicia is a region in north-west Spain, with a population of around 2779000 ; almost 100\% of these people have access to healthcare delivery and $31 \%$ are pensioners. Population density in Galicia is 92.6 inhab $/ \mathrm{km}^{2}$, similar to the European average. Population density decreases as one moves inland from the Atlantic fringe. Consequently, distances to a given population's designated health centre tend to increase. This is how pharmacists become patients' first contact with the health system to consult their health problems.

\section{Holding of focal group sessions}

To work in a community pharmacy in Spain, it is compulsory to be a member of the Official Colleges of Pharmacists (OCP). Using the 'snowball method', the OCP sent project information in the usual way to all community pharmacists. Community pharmacists who were interested in FG participation had to send a reply to the research team. FG sessions were designed to be held with a pre-established number of participants, between 5 and 10 pharmacists in attendance in Galicia.

We sought to ensure a high degree of heterogeneity in the composition of the groups to improve our study's external validity. Pharmacists' participation had no gender or age restrictions, and an effort was made to form FGs with pharmacists who were both owners and non-owners, provided in all cases that they were OCP-registered community pharmacists. Sessions were chaired by 
a moderator who was a specialist in the field, following a script to ensure comparability among groups.

For the purpose of conducting FG discussions, the basic methodological principle of allowing groups to attain their 'own structural identity' was applied..$^{15}$ This afforded an opportunity to discuss individual experiences and then start the group discussion. Only in the latter stages of the FG sessions did the moderator introduce discussion topics (following the script) which had not been mentioned.

FGs were conducted by the principal researcher (JVL). This researcher is specifically trained to develop research using qualitative methodology. FG sessions took place in OCP meeting rooms. Only the investigator/moderator and the participants were present during the FG sessions. All FG sessions were audiorecorded and lasted 45-70 min. The investigator/moderator also took field notes in relation to the attitudes/factors/knowledge explored. The sessions ended when the information being provided by the participants yielded no new ideas. To prevent any possible interpretation biases, the proceedings were transcribed by an independent researcher (MTT).

\section{Ethical considerations}

This study was approved by the Galician Clinical Research Ethics Committee. All the pharmacists were informed of the purpose of the study, of what their involvement entailed, of the objectives, as well as of the fact that the FG sessions would be recorded and transcribed and that no participant would be personally identified in the study results. All of them agreed to participate by signing informed consent.

\section{Analysis}

We used the Grounded Theory Approach. ${ }^{16}$ Analysis of the transcripts was an iterative process undertaken by two researchers working independently (CGG and JVL). The researchers carefully read the transcriptions to structure the data adequately. This allowed for greater in-depth study and familiarisation with the data and decreased the likelihood of researcher bias. Thematic and discursive analysis was used to examine the data, identifying different ideas and sentences that were obtained from the different FGs and organising the topics, with text excerpts serving as units of analysis. The next step was to establish
Table 2 Factors that influence antibiotic dispensing

\begin{tabular}{ll}
\hline Indifference & $\begin{array}{l}\text { Due lack of communication with patient's } \\
\text { physicians } \\
\text { Due to lack of patient follow-up } \\
\text { Due to its priority to sell the antibiotic }\end{array}$ \\
$\begin{array}{ll}\text { External } \\
\text { responsibility }\end{array}$ & $\begin{array}{l}\text { Of patient (inappropriate use) } \\
\text { Of physicians (prescriptions without } \\
\text { indication) } \\
\text { Of healthcare system (private insurances) } \\
\text { Of other professionals (mainly dentists) }\end{array}$ \\
Acquiescence & $\begin{array}{l}\text { Pressure exerted by customers to have the } \\
\text { symptoms speedily resolved }\end{array}$ \\
& $\begin{array}{l}\text { To prevent regular customers consulting } \\
\text { another pharmacy }\end{array}$ \\
Lack of & Dispensing habit \\
continuing &
\end{tabular}

the association between the groups' ideas and the pre-established variables. The researchers then compared the thematic analyses and analysed emerging issues. Any points of disagreement were discussed and resolved by consensus. No computer software was used to analyse the process because the number of FGs was performed was not large.

\section{RESULTS}

Five FGs were formed. Thirty pharmacists $(56.7 \%$ women, $43.3 \%$ men) contacted the research team, and all of them were invited to participate in the FGs. Other characteristics of the FG can be seen in table 1 .

\section{External responsibility}

According to the conclusions of all the groups, one of the most influential variables at play when a pharmacist dispenses an antibiotic without a prescription was external responsibility, an aspect that was considered to lie with two types of health professionals, namely, physicians and dentists.

"I think that doctors also give them (antibiotics) out very easily" (FG5, W1). The external responsibility of

Table 1 Characteristics of focus group composition

\begin{tabular}{lllll}
\hline & \multicolumn{2}{l}{ Sex $\mathbf{n}(\%)$} & & \\
\cline { 2 - 3 } Focus group $(\mathbf{n})$ & Female $\mathbf{( W )}$ & Male $(\mathbf{M})$ & Age range & Practice status owner $\mathbf{n}(\%)$ \\
\hline I (9) & $7(77,8)$ & $2(22,2)$ & $27-32$ years & $0(0)$ \\
II (7) & $2(28,6)$ & $5(71,4)$ & $45-58$ years & $3(42,9)$ \\
III (7) & $4(57,1)$ & $3(42,9)$ & $38-50$ years & $2(28,6)$ \\
IV (5) & $2(40.0)$ & $3(60.0)$ & $45-60$ years & $1(20)$ \\
V (2) & $2(100)$ & $0(0)$ & $42-43$ years & $0(0)$ \\
\hline
\end{tabular}

Our qualitative approach indicated that the influence of the following four variables was considered relevant when it came to dispensing antibiotics over the counter (see table 2). 
physicians was viewed by $100 \%$ of the FGs as being one of the most influential variables underlying the inappropriate dispensing of antibiotics.

Likewise, another important variable was dentists' responsibility. All the FGs agreed that the latter were in the habit of issuing a large number of prescriptions by telephone, that is, "Patients come in saying, I just talked to my dentist and he told me to take an antibiotic for 5 days, and that I must go to his surgery" (FG3; M2). The groups also saw dentists as a source of unnecessary antibiotic prescriptions, that is, "When dentists are going to remove a tooth, they'll prescribe amoxicillin-clavulanate, just like they prescribe ibuprofen" (FG1; M1).

The NHS was rated as being one of the main culprits. Pharmacists said that poor access (space-time) to physicians was an influential factor when antibiotics were dispensed without medical prescription, that is, "Another problem is all the time it takes to see a doctor: access is always faster at a pharmacy" (FG2; M2).

Another important variable was the number of prescriptions prescribed in private insurance versus the NHS, with most FGs reporting that is, "Ten times more antibiotics are given in private insurance than in the NHS" (FG2; M1).

\section{Lack of continuing education}

Lack of continuing education was considered a relevant factor by $80 \%$ of the FGs $(4 / 5)$ in any case where a pharmacist dispensed antibiotics without a prescription. As shown above, lack of continuing education can be viewed from different standpoints, for example, "In specific diseases, there is a range of antibiotics, and you start with the oldest" (FG3; W3). In this case, it shows the lack of knowledge about starting with the first-line antibiotic, which is not always the oldest.

Age is also referred to as a key variable to explain the existence of lack of continuing education, with older pharmacists being those who exhibit this deficit. "Older pharmacists give out antibiotics much more readily. '(FG2, M1), and, 'Young people give out fewer antibiotics" (FG3; W3).

Another aspect mentioned and related to lack of continuing education is the consideration of the problem of resistance as a recent phenomenon. "I think that the issue of resistance has begun recently, not so long ago..." (FG1, W2).

\section{Acquiescence}

In the five FGs (100\%), acquiescence was seen as an important variable, that is, "Many people give antibiotics to retain patients" (FG4; W1). A contributory factor was the different treatment accorded to regular and non-regular customers, that is, "Sometimes, I give them to regular patients" (FG1; M1).

In essence, acquiescence is yielding to pressure when a certain patient wants an antibiotic: "When you know the customer, you try to convince him, but in the end, if he keeps on insisting, you give it to him" (FG2; W1); and, "If they come to get amoxicillin and then start insisting, you give it to them" (FG5; W1). Indeed, 60\% of the FGs regarded patient pressure as an important factor when it came to dispensing antibiotics without a prescription. From the pharmacists' viewpoint, the current percentage ranges from $5 \%$ to $20 \%$.

\section{Indifference}

Participants indicate the existence of indifference and mutual consent between community pharmacists and other healthcare professionals, chiefly physicians, along with inappropriate attitudes to prescribing and dispensing antibiotics, noting the lack of communication as indirectly associated with indifference, that is, "I will give you amoxicillin-clavulanate... but you go to your doctor and bring me the prescription. That way, I feel I'm blameless" (FG5; W2).

In a third FG, the following statements were made: "The two professions are hardly involved with each other, there are no close ties, so that we criticise our mistakes but don't value our successes'; and, 'Sometimes I dispense an inappropriate antibiotic because I don't have the time to contact the patient's physician" (FG2; W1) (box). In this case, they identify communication difficulties as the cause of inadequate dispensation but show indifference about solving the problem.

We also observed the existence of Indifference about transmitting adequate information about the problems of resistances to customers who go to the pharmacy to buy antibiotics, as Indifference is another possible way to contribute to developing microbial resistances. "Ok, I see, but this is about their (people's) difficulty to understand, I mean, surely, if you talk to somebody about resistance, it will sound familiar to them, but trying to explain to them how resistances are generated..., you know what I mean, an effective way to make them understand that, if they take this or that antibiotic without needing it, it's not going to have any effect later on" (FG1, W2).

Finally, another aspect that is framed within indifference is the fact that, in Spain, the pharmacist is also a businessman. "In addition to being healthcare professionals, we are also businessmen" (FG2; M2), so, in addition to the individual's health, they are concerned about the profitability of the business. This statement reflects this attitude: 'Take it with you. If you get better, don't take it, just bring it back to me! ... and most people bring it back" (FG2; W1). This sentence also refers to what we call 'delayed dispensing' which is related to delayed prescriptions. Delayed prescriptions are those that are written but are only used if the symptoms do not improve. ${ }^{17}$ Delayed dispensing of antibiotics can thus be defined as the dispensing of antibiotics for a patient, on the condition that they are not to be used immediately but only in the event that the symptoms fail to improve.

\section{DISCUSSION}

This is the first qualitative study to be conducted in Spain that explores pharmacists' knowledge of and attitudes towards antibiotic use and its relationship with microbial resistance. Our study shows that antibiotics dispensed without medical 
prescription was attributed to acquiescence, indifference and lack of continuing education. The problem of resistance was ascribed to lack of continuing education, indifference and external responsibility, including patients, physicians, dentists and the NHS.

We chose a qualitative design to perform this study because it helped us to better understand the processes and realities of the problems currently confronting public health. ${ }^{18}$ We were interested in a full, detailed description as well as conceptual analysis and theory generation. As there was a theory that we could corroborate and it was hoped that a theory might arise from systematically collected data, the grounded theory offered the most appropriate method. ${ }^{19}$ The use of the FG in the sphere of health is indicated and validated in works where the aim is to investigate what participants think and why, enabling data to be generated which could not be attained by other techniques. ${ }^{20} 21$

Antibiotics dispensed without medical prescription is a problem in Spain. The statements made in the different FGs corroborate the conclusions of previous studies, namely, that antibiotic dispensing without a prescription is a phenomenon that exists in Spain. ${ }^{22}{ }^{23}$ This conclusion was reached by all the FGs, notwithstanding the fact that there were small variations among them in terms of pharmacists' opinions regarding the attitudes responsible for this practice. Evidence has been provided to show that the dispensing of antibiotics without medical prescription reaches $30 \%$ in Spain. ${ }^{13}$ Our study reveals that, from the pharmacists' viewpoint, the current percentage ranges from $5 \%$ to $20 \%$, although they thought that this percentage may have been underestimated.

Our findings are reinforced by studies conducted elsewhere. As in our case, in these other settings, a prescription is required to obtain an antibiotic, and a high percentage of self-medication and antibiotics dispensed without medical prescription at community pharmacies was likewise detected. ${ }^{24}$ Nevertheless, the estimates of the pharmacists who participated in our FGs were lower than those of other studies conducted in the same environment. The latter studies placed the percentage of antibiotics dispensed without prescription at $65.9 \%{ }^{25}$ These results were only to be expected, however, as the pharmacists that we questioned about inappropriate dispensing were the very ones responsible for doing this.

Analysis of lack of continuing education showed a difference between professionals of different ages. This situation may be due to: (1) increased training of new professionals in the antibiotics field, as it is in the last 10 years when the problem of resistance has had major social, scientific and clinical repercussions; (2) the fact that younger people are usually not pharmacy owners, which means that sales levels have no direct impact on their salaries and that any request to dispense antibiotics without a prescription will therefore be met with a firm refusal and (3) the fear factor. This factor is possibly linked to the major fear felt by young pharmacists about dispensing antibiotics, as found in a study of physicians performed in our area. ${ }^{14}$ However, none of the
FGs mentioned this variable, so it is necessary to interpret it very cautiously.

Studies conducted in other settings using the same methodology have reached similar conclusions regarding the variables influencing the time taken to dispense an antibiotic and the external responsibility of physicians and patients. However, they also attach great importance to other variables, such as economic interest. ${ }^{26}$ Economic interest is strongly linked to variables such as patient loyalty, for example, in our environment, the dispensing of non-prescription antibiotics was found to increase in cases where patients were known. ${ }^{23} \mathrm{~A}$ study conducted in our setting concluded that there was an association between the pharmacist's age, the fact of owning a pharmacy, the patient's age and sex and the workload in terms of higher or lower drug-dispensing levels. While these results cannot be directly extrapolated to our study because they would have to be restricted to antibiotic dispensing, they nonetheless show the variables that have an impact when a drug is dispensed, and these have proved to be relevant in our study. ${ }^{27}$ The fact that, in Spain, some community pharmacists are also business owners is a factor that has not been taken into account in studies conducted in this population. This variable emerged directly in one FG and indirectly in others.

The difficulty of spatiotemporal access to physicians was another variable that emerged in the FGs. There is evidence in the literature to confirm that the proximity of a pharmacy decreases the demand for primary care. ${ }^{28}$ Lack of communication with other health professionals, particularly physicians, due to different variables such as the attitudes and perceptions of different professionals is an aspect that has already been studied in our setting. ${ }^{29}$ Our study reinforces the idea of the need to improve pharmacist training programmes and the relationships among health professionals.

Acquiescence is a factor that has been studied by other research groups. The ease with which an antibiotic is dispensed to a patient is a variable that other studies have confirmed. ${ }^{30}$ Our results are comparable with those yielded by other professionals in the same setting. Conclusions reached about physicians show that the determinant factors of antibiotic prescribing are fear, acquiescence, lack of continuing education and external responsibility. ${ }^{13}$ Factors such as lack of continuing education and external responsibility show great influence in both studies when it comes to prescribing and dispensing antibiotics. ${ }^{130}$ Both studies report the external responsibility of other professionals as being one of the main sources of malpractice, that is, the notion of other professionals being perceived as the main culprits. Indeed, external responsibility is a common variable among health professionals, especially those who state that they have no time to give explanations, and this is the reason for their malpractice. ${ }^{13} 30$

Our results are also comparable to those of a recent qualitative study undertaken in Portugal. This paper concludes that attitudes related to the problem of resistance were attributed to the external responsibility of patients, 
physicians, other pharmacists and veterinarians. ${ }^{31}$ In our study, external responsibility was attributed to physicians, dentists and the NHS. These results are extremely interesting because these attitudes, which were identified in two different countries, could clear the way to designing specific interventions at a Euro-regional Galicia-Northern Portugal level.

\section{Strengths and limitations}

One limitation is the low number and the source of the participants (community pharmacists from a specific area of Spain who are not necessarily representative of all community pharmacists working in Spain), an aspect that restricts the study's generalisation to other areas or countries. The generalisation of the results could also be compromised due to the intrinsic characteristics of the pharmaceutical system in Spain, governed by laws that may differ with respect to other countries. However, the study conducted in Portugal yielded similar results. ${ }^{31}$ In any case, qualitative methods can seek to obtain a range of views, and generalisability of findings is not usually an expected attribute of this type of research. Can be seen the COREQ checklist of consolidated criteria for reporting qualiative studies at suppplemntary materials. Similarly, the nature of qualitative data is that it is jointly constructed by the researcher and the participants and cannot be viewed as objective accounts. ${ }^{160}$ Another possible study limitation is that one of the FGs failed to attain the pre-established minimum number of participants. Nevertheless, the conclusions drawn from this FG did not differ significantly from those of the other groups. Among the study's advantages is the fact that interaction among FG members generated ideas about antibiotics and resistances, which would otherwise have been difficult to obtain. ${ }^{16}$ There are several previous studies that corroborate our findings both in our own and in other settings, thereby increasing the reproducibility and validity of our study. ${ }^{1322} 2629$

\section{CONCLUSIONS}

Once attitudes/knowledge associated with inappropriate dispensing have been identified, interventions can be designed to focus on these shortcomings, so as to improve antibiotic use and contribute to minimising resistance. ${ }^{32}$ Pharmacotherapy-based interventions with community pharmacists must be undertaken to prevent errors due to lack of knowledge. This also implies the need to bear in mind the specific functions of pharmacists as health professionals. Not only are publicity campaigns to reduce antibiotic use necessary, but they need to be more direct if they are to have a major impact on health professionals and the general population alike.

Contributors V-LJM: conception and design of the study; design and conduct focus groups;contribution to peer review of the transcription data; analysis and interpretation data; writing of the different versions of the manuscript and review of the final approval of the work. G-GC: design and conduct focus groups; analysis and interpretation data and review of the final approval of the work. Z-CM: writing of the different versions of the manuscript and review of the final approval of the work. L-VP: analysis and interpretation data and contribution to peer review of the transcription data. TM: transcription of audio data. LA: conception and design of the study; design the focus groups and contribution to peer review of the transcription data. FA: drafting the work and revising it critically for important intellectual content and final approval of the version to be published.

Competing interests None declared.

Ethics approval Ethics Committee Investigation of Santiago-Lugo.

Provenance and peer review Not commissioned; externally peer reviewed.

Open Access This is an Open Access article distributed in accordance with the Creative Commons Attribution Non Commercial (CC BY-NC 4.0) license, which permits others to distribute, remix, adapt, build upon this work non-commercially, and license their derivative works on different terms, provided the original work is properly cited and the use is non-commercial. See: http://creativecommons.org/ licenses/by-nc/4.0/

C Article author(s) (or their employer(s) unless otherwise stated in the text of the article) 2017. All rights reserved. No commercial use is permitted unless otherwise expressly granted.

\section{REFERENCES}

1. Baquero F, Baquero-Artigao G, Cantón R, et al. Antibiotic consumption and resistance selection in Streptococcus pneumoniae. $J$ Antimicrob Chemother 2002;50:27-38.

2. Goossens H, Ferech M, Vander Stichele R, et al. Outpatient antibiotic use in Europe and association with resistance: a cross-national database study. Lancet 2005;365:579-87.

3. Costelloe C, Metcalfe C, Lovering A, et al. Effect of antibiotic prescribing in primary care on antimicrobial resistance in individual patients: systematic review and meta-analysis. BMJ 2010;340:c2096.

4. Spellberg B, Powers JH, Brass EP, et al. Trends in antimicrobial drug development: implications for the future. Clin Infect Dis 2004;38:1279-86.

5. Safrany N, Monnet DL. Antibiotics obtained without a prescription in Europe. Lancet Infect Dis 2012;12:182-3.

6. Alliance for the Prudent Use of Antibiotics. Executive summary: select findings, conclusions, and policy recommendations. Clin Infect Dis 2005;41:224-7.

7. Okeke IN, Laxminarayan R, Bhutta ZA, et al. Antimicrobial resistance in developing countries. Part I: recent trends and current status. Okeke IN, Klugman KP, Bhutta ZA, et al. Antimicrobial resistance in developing countries. Part II: strategies for containment. Lancet Infect Dis 2005;5:568-80.

8. Okeke IN, Klugman KP, Bhutta ZA, et al. Antimicrobial resistance in developing countries. Part II: strategies for containment. Lancet Infect Dis 2005;5:568-80.

9. Real Decreto Legislativo 1/2015. de 24 de julio, por el que se aprueba el texto refundido de la Ley de garantías y uso racional de los medicamentos y productos sanitarios

10. Morgan DJ, Okeke IN, Laxminarayan R, et al. Non-prescription antimicrobial use worldwide: a systematic review. Lancet Infect Dis 2011;11:692-701.

11. Campos J, Ferech M, Lázaro E, et al. Surveillance of outpatient antibiotic consumption in Spain according to sales data and reimbursement data. J Antimicrob Chemother 2007;60:698-701.

12. García Calvente e MM, Mateo Rodríguez I, Rodriguez M I. El grupo focal como técnica de investigación cualitativa en salud: diseño y puesta en práctica. Atención Primaria 2000;25:181-6.

13. Lopez-Vazquez P, Vazquez-Lago JM, Figueiras A. Misprescription of antibiotics in primary care: a critical systematic review of its determinants. J Eval Clin Pract 2012;18:473-84.

14. Vazquez-Lago JM, Lopez-Vazquez P, López-Durán A, et al. Attitudes of primary care physicians to the prescribing of antibiotics and antimicrobial resistance: a qualitative study from Spain. Fam Pract 2012;29:352-60.

15. Bohnsack R, A Companion to Qualitative Research. Group discussion and focus groups. In: Flick U, von Kardoff E, Steinke I, eds. Sage, London, UK, 2004;24:221.

16. Corbin JM, Strauss A. Grounded theory research: Procedures, canons, and evaluative criteria. Qual Sociol 1990;13:3-21.

17. Arroll B, Kenealy T, Goodyear-Smith F, et al. Delayed prescriptions. BMJ 2003;327:1361-2.

18. March Cerdà JC, Prieto Rodríguez MA, Hernán García M, et al. Técnicas cualitativas para la investigación en salud pública y gestión de servicios de salud: algo más que otro tipo de técnicas. Gac Sanit 1999;13:312-9. 
19. Corbin J, Strauss A. Basics of Qualitative Research. Techniques and procedures for developing grounded theory. Sage, London, UK, 2008.

20. Kitzinger J. The methodology of focus groups: the importance of interaction between research participants. SHI 1994;16:103-21.

21. Aigneren M. La técnica de recolección de información mediante los grupos focales. CEO 2006:1-19.

22. Zapata-Cachafeiro M, González-González C, Váquez-Lago JM, et al. Determinants of antibiotic dispensing without a medical prescription: a cross-sectional study in the north of Spain. J Antimicrob Chemother 2014;69:3156-60.

23. Llor C, Cots $\mathrm{JM}$. The sale of antibiotics without prescription in pharmacies in Catalonia, Spain. Clin Infect Dis 2009;48:1345-9.

24. Sabry NA, Farid SF, Dawoud DM. Antibiotic dispensing in Egyptian community pharmacies: an observational study. Res Social Adm Pharm 2014;10:168-84

25. Caamaño Isorna F, Tomé-Otero M, Takkouche B, et al. Factors related with prescription requirement to dispense in Spain. Pharmacoepidemiol Drug Saf 2004;13:405-9.

26. Kotwani A, Wattal C, Joshi PC, et al. Irrational use of antibiotics and role of the pharmacist: an insight from a qualitative study in $\mathrm{New}$ Delhi, India. J Clin Pharm Ther 2012;37:308-12.
27. Caamaño-Isorna F, Montes A, Takkouche B, et al. Do pharmacists' opinions affect their decision to dispense or recommend a visit to a doctor? Pharmacoepidemiol Drug Saf 2005;14:659-64.

28. Carrasco-Argüello A, Iglesias-Rey M, Pardo-Seco J, et al. [Proximity to the pharmacy and health care demand in primary care]. Aten Primaria 2013;45:172-3.

29. Rubio-Valera M, Jové AM, Hughes CM, et al. Factors affecting collaboration between general practitioners and community pharmacists: a qualitative study. BMC Health Serv Res 2012;12:188.

30. Barbero-González A, Pastor-Sánchez R, del Arco-Ortiz de Zárate $\mathrm{J}$, et al. [Demand for dispensing of medicines without medical prescription]. Aten Primaria 2006;37:78-87.

31. Roque F, Soares S, Breitenfeld L, et al. Attitudes of community pharmacists to antibiotic dispensing and microbial resistance: a qualitative study in Portugal. Int J Clin Pharm 2013;35:417-24.

32. Arnold SR, Straus SE. Intervenciones para mejorar las prácticas de prescripción de antibióticos en la atención ambulatoria (Revisión Cochrane traducida). Biblioteca Cochrane Plus 2006. Oxford: Update Software Ltd, http://www.updatesoftware. com (accessed 20 Apr 2014). 